\title{
Students' Views about Their Participation in a Philosophy Program
}

\author{
Renia Gasparatou, Marida Ergazaki \\ Department of Educational Sciences \& Early Childhood Education, University of Patras, Patras, Greece \\ Email: gasparat@upatras.gr, ergazaki@upatras.gr
}

Received 6 April 2015; accepted 16 May 2015; published 19 May 2015

Copyright (C) 2015 by authors and Scientific Research Publishing Inc.

This work is licensed under the Creative Commons Attribution International License (CC BY).

http://creativecommons.org/licenses/by/4.0/

c) (i) Open Access

\begin{abstract}
This paper reports on a phenomenological study that aims at exploring students' own perception of their participation in a "Philosophy for/with Children" program. The program was comprised of eight philosophy sessions designed for stimulating interesting and fairly disciplined discussions. The implementation of the program took place at a village high school in a rural part of west Greece, with 16 teenager students (age 14 - 16). The students gave us individual semi-structured post-interviews concerning (a) the expectations they had from the program, (b) their experience from it, (c) their understanding about its purpose and outcomes, and (d) their suggestions for possible changes with regard to it. The qualitative analysis of students' interviews showed that they had a very positive view of the program, as thoroughly discussed in the paper.
\end{abstract}

\section{Keywords}

Philosophy Sessions, Philosophy for/with Children, High School, Phenomenological Study

\section{Introduction}

In this paper we will outline a "Philosophy for/with Children" (thereafter P4C) program that took place at a village high school in a rural part of west Greece, in the beginning of 2014. We will focus on children's perception of this program.

Advocates of the P4C movement, which started with Lipman in the 70's, argue for the introduction of philosophy sessions at schools. Many reasons are articulated in favor of P4C programs: they are expected to foster critical thinking, reasoning and argumentation; support linguistic skills; promote democracy by the advancement of trust in a community of enquiry in which the educator is merely a facilitator (Fisher, 2001; Haynes, 2008; Haynes \& Murris, 2012; Lipman, 1982, 1988, 1991; Matthews, 1980; Murris, 2000; Splitter \& Sharp, 1995; Worley, 2011).

Many P4C programs have since being held around the globe and today there is a lot of empirical research 
claiming that philosophy programs deliver their goals (Daniel \& Delsol, 2005; Daniel \& Gagnon, 2011; Daniel et al., 2011; Follman et al., 1997; Reznitskaya et al., 2008; Reznitskaya et al., 2009; Reznitskaya, 2012; Reznitskaya et al., 2012; Riley, 2013). Many inventories have been developed for measuring critical thinking, performance in dialogue and argumentation, linguistic skills etc. Studies claim that participants of P4C score higher in linguistic skills, critical thinking skills, and argumentation skills; but also in self-esteem measurements, academic achievement and so forth (Delsol, 2005; Daniel \& Gagnon, 2011; Daniel et al., 2011; Daniel \& Reznitskaya, 2012; Reznitskaya et al., 2008; Reznitskaya et al., 2009; Reznitskaya et al., 2012; Stokes, 2012; Trickey \& Topping, 2004; Topping \& Trickey, 2007; Youssef, 2014). It is just commonsensical however to claim that, despite these overwhelming data, there are many difficulties in measuring the overall effectiveness of a P4C program and/or excluding other factors that could also affect the results of such studies. Critics also express some skepticism about the instrumentalization of philosophy that such studies imply (Biesta, 2011; Gregory, 2011; White, 2012). In their view, philosophy should not be implemented as an instrument for the accomplishment of other academic or personal goals. Another line of criticism still suggests that children cannot philosophize since they have not yet fully developed their abstract thinking or their meta-cognitive skills (Gregory, 2011; Matthews, 1980; Murris, 2000; White, 2012).

In this paper, we will let children talk for themselves. Our aim is to highlight how they experienced their participation in the program. We believe it is an important starting point for the assessment of any educational practice to explore what the participants think of it. Especially a practice that campaigns on the advancement of democratic education ought to ask participants how they perceived their participation. Here we will try such a phenomenological approach.

We do not feel that this makes us immune to the criticisms mentioned above. Neither do we wish to be so. In fact, we feel that our strategy partly helps addressing some of the criticisms by letting children speak for themselves about the program's influence on them. For example, we might get some clues about what motivates children to participate in such programs. It would be interesting to see whether their academic development is among their motives. Or if they believe philosophy fosters some skills; and which skills are they. Also it is important to examine if they seem to value philosophy for its own sake. So, it would be very useful to see what they believe the point of these sessions is and whether they feel the program benefited them somehow.

Our program was implemented in a high school and the participating children were teenagers, aged 14 - 16. Now, according to developmental theories, teenagers typically have started developing their metacognitive skills (Kuhn \& Park, 2005). And some systematic help would probably benefit the advancement of such skills. A phenomenological study cannot examine if the philosophy sessions improved these skills. But it can help us understand whether children recognize them and if they feel they are worth developing. Also whether they feel philosophy sessions can help this process. Moreover, it is important to see how they feel during such discussions: Are they too demanding for them? Do they feel pressured? Or do they enjoy taking part?

Before outlining our study, we should note that the Greek school system—which includes basic education (1 year in kindergarten, 6 years in elementary school and 3 years in high school) and compulsory education (3 years either in secondary or technical school)—follows a curriculum where philosophy appears only once, as an optional course for one hour per week in the second class of secondary school. Students are taught theories of philosophy through its history, typically by literature teachers. The Greek school curriculum does not contemplate any other kind of philosophy sessions for students. In fact, any coordinated attempts to practice P4C have been limited to a few research programs. And, as far as we know, the only one practiced in high school is the one we will present here.

In designing these sessions, we tried to stay focused on one philosophical problem each time. We tried not to prepossess any other goals apart from the fact that we wanted to stimulate interesting and fairly disciplined discussions (Gregory, 2007). However, we were-and still are-motivated by a poster we once saw: "P4C: Challenging the mind, cultivating the heart". More specifically, we feel a philosophy program should foster a trusty community of enquiry, so that actual enquiry can take place. Interesting questions, interesting views and interesting arguments should be exchanged, so that all participants would promote their epistemic faculties and their character traits and reach a better understanding of the topic in question. Regardless of our views, we did not set any specific goals when talking to the students.

Thus, in this paper, we explore how students felt during the program, how they think it influenced them and what they proposed we change. Thus, our research question here is "How did students experience their participation in a sequence of philosophy sessions that aimed at stimulating interesting and fairly disciplined discus- 
sions?”.

\section{Methods}

\subsection{The Overview of the Study}

This paper reports on a phenomenological study within the qualitative research paradigm (Johnson \& Christensen, 2004). The study includes (a) designing and implementing a philosophy program for teenagers, and (b) exploring how this program worked, through the eyes of the high school students who took part in it. The implementation of the program took place at a village high school, which we visited every Sunday morning for 8 weeks (mid-February to mid-April). An introductory session, that informed students about the program, was followed by a sequence of six philosophy sessions and finally by a closing one where students gave us feedback on how they viewed the program themselves.

\subsection{The Participants}

The participants of the study were 14 - 16-year-old students of a high school in a rural area of north-west Peloponnese, about $40 \mathrm{~km}$ from Patras, Greece. The reasons for selecting this high school were: (a) teachers' willingness to facilitate our research, and (b) students' profile, which made the implementation of a philosophical program rather challenging. The school attracted students from the whole area: rural Greece has many small villages and only some of them have schools, so the rest of the children have to travel some kilometers for their lessons. All participants came from lower-to-middle class families. They were all members of the "environmental club" of their high school, which met on Sundays, and in which we also integrated our program. Participation was optional, both for the "environmental club" and for the P4C program. 16 out of the 20 students, who participated in the "environmental club", came to the P4C program as well. 9 of them were girls and 7 were boys. None of them had participated in a P4C program or any other philosophical activity, none was taught philosophy in any way, and none had been involved in any "critical-thinking" or "rhetoric" group of any sort since then.

\subsection{The Program}

The program started with an introductory session: we introduced ourselves and told students what we were going to do together (discuss, philosophize); then, we all agreed on some ground-rules for our philosophy-sessions (e.g. each will wait for their turn before talking, we will listen carefully to what our classmates say, we will be polite, etc.). What actually followed was a sequence of six philosophy sessions, each devoted to a particular topic, students' interviews and a closing session (Table 1).

We decided that all topics should be loosely related with moral issues (friendship, obedience and rules, moralaction and consequences, freedom, identity, diversity \& equality). We thought that the topics should be related to each other, so that there would be a continuum in the discussions and students' reasoning could go deeper. We chose issues we thought students would find familiar and interesting. Also, since most of these issues are really hot potatoes in Greece today, especially rural Greece, we found it rather important to engage students in exploring

\begin{tabular}{cl}
\begin{tabular}{c} 
Table 1. Topics per session. \\
\hline Session
\end{tabular} & \multicolumn{1}{c}{ Topic } \\
\hline 1 & Introduction: What are we going to do here on Sundays? \\
2 & What is a friend? (Friendship) \\
3 & Why are there rules? (Rules \& obedience) \\
4 & When is an action a moral one? (Consequentialism) \\
5 & Do we choose who we are? (Freedom) \\
6 & What is it to be you? (Personal Identity) \\
7 & Are you like the others? (Diversity \& equality) \\
8 & Coda: What do we think about our discussions? \\
\hline
\end{tabular}


them in a relaxed, yet systematic manner. In each philosophy session, we presented students with a thought experiment or scenario. We preferred thought experiments because they (a) tell a story that helps children empathize with the subject matter; yet (b) they are designed in a way that they shift attention to the philosophical question itself.

There seems to be a gap in P4C bibliography about triggers for this age group. We thus modified three thought experiments from Worley (2011) and his If-machine: “Ceebie-stories: Friends” (session 2), “The lie” (session 3), and "The Android" (session 7); we also used two versions of the trolley problem (session 4); and we assembled some scenarios of our own (sessions 5 - 6). The scenario was always displayed on a projection screen. After the discussion of the scenario (or the scenarios) and an initial overview of the worries it poses, we introduced the main question of the session. It was also displayed and it remained on display until the end of the session, so that students could stay focused. Besides the screen, there was a blackboard in which the facilitator (AU1) wrote students' ideas, made connections between them or marked arguments and counter-arguments.

In this way, students were introduced to a philosophical problem through a story and took the time to familiarize themselves with it before pursuing the main question. However, after the question was suggested, one wouldn't have to appeal to the scenario again. Sometimes students used elements of the scenario as arguments, but sometimes they made up their own examples or counter-examples, and used them as arguments during discussion. All sessions were audio-recorded and fully transcribed, although we are not concerned with these data here.

After the 6 philosophy sessions, we met again in order to get feedback from the participants. Each student gave an individual semi-structured interview, whereas the rest of us walked and took pictures in the schoolyard. After the interviews were over, we were all gathered inside the classroom for an overall final discussion of what students liked or disliked during the program. That was the closing session.

The two authors collaborated in organizing the whole research. During the sessions though, they had different roles: AU1 (philosopher) was the facilitator, while AU2 (educational researcher) sat aside, making sure for the recordings and taking notes. AU2 was also the one that interviewed the students; they were comfortable with AU2, yet less attached and thus freer to express how the felt and what they thought about the program and the facilitation. However, it is worth noticing that when AU1 facilitated the last session, the feedback was very similar with what children individually said to AU2 in the interviews. In any case, in this paper we will focus on the individual interviews the participants gave us.

\subsection{The Interview Protocol}

The protocol of the semi-structured interviews was comprised of 10 open-ended questions that aimed at highlighting students' own views about the program (see Appendix). First of all, students were asked about the reasons for which they decided to participate in the program (Q1). This way their motives for taking part, as well as their expectations from the program, could possibly emerge. Moreover, we attempted to trace students' experience from the program by asking them whether they enjoyed the sessions (Q2), how they felt during the discussions that took place (Q3), how they felt afterwards (Q4), and whether they would like to take part in a similar program if we decided to run one next year (Q5). Another set of questions was integrated in the protocol in order to track students' own understanding about the purpose of the program (Q6) and the ways it possibly affected them as persons in general (Q7) and as discussants in particular (Q8). Finally, students' suggestions for possible modifications regarding the program were also elicited (Q9, Q10).

\subsection{The Overview of the Analytic Procedure}

The tape-recorded interviews were transcribed and prepared for coding within the environment of "NVivo", a qualitative data-analysis software. The categories of our coding scheme emerged from students' responses at each open-ended question and are thoroughly discussed in the results' section. The coding was performed independently by the two authors and the inter-rater reliability was satisfactory (Cohen’s kappa: 0.90).

\section{Findings}

In this section, we will outline our findings about (a) the expectations students had form the program, (b) their experience from it, (c) their assessment of the skills they felt they were supposed to acquire from the program 
and those they felt they did acquire, and finally (d) their suggestions for possible changes regarding the program. To make a long story short, we here summarize our findings about students' own perception of the program.

\subsection{Students' Expectations from the Program}

Q1: Why did you choose to participate in this program in the first place?

Our findings from the analysis of students' responses to Q1 (Why did you participate in the program?) showed that their motives for participating and thus their expectations from the program were the following:

- Improve thinking/argumentation skills: This is one of the two most frequent categories of students' responses (Table 2). In their own words, what students thought they would gain from the program was "learn to justify" what they say or "be able to ground" their views.

- Try something new, different, and interesting: This is an equally frequent category of responses with the first one (Table 2). In students' own words, they expected to work with something they "hadn't tried before" and would be "different" or "interesting" to them.

- Get familiar with philosophy: Joining in in order to familiarize with philosophy was also a quite frequent expectation on behalf of the students (Table 2). In their own words: "I was curious to see what philosophy is all about"; "You hear about philosophy, but you can't understand what it is they do exactly".

- Relate to schoolmates: Although not actually frequent (Table 2), this category dictates a rather interesting expectation from the program. The group meetings were considered as a way for improving social skills and "learning how to relate with others" by one of the students.

- Improve linguistic \& dialogue skills: This is an equally rare category with the previous one (Table 2). Just one student appeared to expect that he "should learn how to talk and not always jump in a discussion".

\subsection{Students' Experience from the Program}

Students' experience from the program was traced by asking them whether they enjoyed the sessions (Q2), how they felt during the session discussions (Q3), how they felt afterwards (Q4), and whether they would like to take part in a similar program if we decided to run one next year (Q5). Our analysis of students' responses to these questions showed the following:

Q2. Did you enjoy the P4C sessions?

All students said they enjoyed their participation in the program (Table 3). 11 replies suggest that students felt that the program stimulated their thinking, enquiry and argumentation skills. "I put my mind at work", "We were analyzing stuff", "We discussed so many different ideas every time", were some of the phrases they used to show that they enjoyed the whole process. Moreover, 5 replies suggest that students felt the sessions promoted a sense of community that they enjoyed. As they said, they felt they "were a team", "there was companionship" or

Table 2. Categories of student's responses to Q1.

\begin{tabular}{cc}
\hline Categories of students' responses to Q1 & Frequency (times of appearance) \\
\hline Improve thinking \& argumentation skills & 5 \\
Try something new, different, interesting & 5 \\
Get familiar with philosophy & 4 \\
Relate to schoolmates & 1 \\
Improve dialogue \& linguistic skills & 1 \\
\hline
\end{tabular}

Table 3. Categories of student's responses to Q2.

\begin{tabular}{cc}
\hline Categories of students' responses to Q2 & Frequency (times of appearance) \\
\hline Yes: Stimulation of thought, enquiry, argument & 11 \\
Yes: Sense of community & 5 \\
Yes: Interesting topics & 3 \\
\hline
\end{tabular}


they "were with [their] friends". Finally, 3 replies suggest that students liked the program because of the interesting topics they discussed. In their own words, “The things we discussed were very interesting; we couldn't stop thinking about them".

Q3. How did you feel during the discussions?

The most frequent category of students' responses to how they felt during the discussions that took place in the philosophy sessions was "joy \& enthusiasm”: "I felt fine”, “All full of enthusiasm”, "I was so happy I was here". Many students as well, suggested they felt "discomfort", in the sense of uneasiness or anxiety: "I felt very uneasy when we wrote and erased [ideas from the blackboard]", "It was disturbing to disagree”, "At first I felt a little bit uncomfortable when I was talking; but after a while it was fine". Some also said they were "bored" at times "depending on [their] mood", or because they felt they "got lost in the discussion". One student said she felt "free and responsible" because we "made [them] think", we made them "say what [they] would do" or "how [they] see things". She liked that she was free to talk or free to think of many alternatives, but she also liked that she felt accountable for whatever she said and thought. Another student emphasized how important it was for him "to feel as a member of a community". And finally, another one said she felt "pride" during the discussions "because [she] could think of something to say" (Table 4).

Q4. How did you feel after the discussions? Did you think about what you discussed?

When asked how they felt and what they thought after the sessions, most students said that they kept discussing the topics with others or kept thinking about them by themselves. More specifically, the category "sharing with others" appeared 15 times. In other words, 15 students said they discussed the session topics afterwards with friends and family ("with [their] sisters" or "at Sunday lunch when [they] get home"). A boy from a breeder family said "Sure, I asked my grandmother what she would do with the train [i.e. the trolley problem]; we still talk about it whenever we feed the sheep".

Moreover, the category "reflecting when alone" appeared 12 times: students said they kept thinking about the things we discussed on their own "before [they] go to bed" or "whenever [they are] alone". Finally, "discomfort \& joy" felt during the sessions, also accompanied one student afterwards. She describes a mixed feeling of uneasiness and excitement that was rather pleasant: “I was uneasy when I didn't know what to think and happy as well for wondering, or sometimes I was uneasy at first, but happy when I made up my mind” (Table 5).

Q5. If we run a similar program next year, would you like to take part in it?

When asked whether they would like to take part in a similar program next year if we run one, all students said they would. As shown in Table 6, their justifications very often imply they would like to discuss again topics that interest them and analyze them in depth: "I'd come again for the topics", I would like to have "more such interesting topics to discuss", "I would like to be able to analyze more subjects". Students also suggest they felt that a second program would be a good exercise of their critical thinking skills and would help them during

Table 4. Categories of student's responses to Q3.

\begin{tabular}{cc}
\hline Categories of students' responses to Q3 & Frequency (times of appearance) \\
\hline Joy, enthusiasm & 15 \\
Discomfort & 10 \\
Boredom & 2 \\
Freedom \& responsibility & 1 \\
Member of community & 1 \\
Pride & 1 \\
\hline
\end{tabular}

Table 5. Categories of student's responses to Q4.

\begin{tabular}{cc}
\hline Categories of students' responses to Q4 & Frequency (times of appearance) \\
\hline Sharing with others & 15 \\
Reflecting when alone & 12 \\
Discomfort \& joy & 1 \\
\hline
\end{tabular}


any kind of enquiry (“experience enquiry \& critical thinking”). In their own words, they would welcome the opportunity "to continue getting better at looking at things from both sides", "to understand complicated stuff", "to see the consequences of each side", "to be able to analyze everything deeply".

"Joy" was a frequent category of responses, as well. 6 students mentioned they would do a program again because "they enjoyed it" in the first place and "it would be fun to do it again". This feeling of pleasure was again and again emphasized during the final group meeting, too. All students said they enjoyed it and they would like to do it next year just for the pleasure of it. 5 children said they would like to improve more their dialogic skills, "learn more how to discuss" or "learn to express [themselves] better". 4 students said they would like to have this sense of belonging in a community once more, "to get together" and "be a group again". Finally, one student said "it helped [her] with other courses at school" (Table 6).

\subsection{Students' Understanding of the Program's Purpose and Outcomes}

Students' understanding of the program's purpose and outcomes was traced by asking them what they thought we wanted them to learn from the program (Q6) and whether they felt that the program benefited them as persons in general (Q7) and as discussants in particular (Q8). Our analysis of students' responses to these questions showed the following:

Q6. What do you think was the purpose of this program? Is there something you believe we wanted you to learn or understand?

As shown in Table 7, most students felt that the program aimed at promoting dialogue and tolerance. They said we wanted them "to learn how to listen to the others", "to communicate better", "to understand the others and discuss with them". Students also thought that our purpose was to help them with skills that are related to "enquiry, critical thinking and argument". In their own words, we wanted them to "learn how to think", "learn to examine something from different perspectives". Finally, the "clarification of concepts" was also thought as a possible objective of the program, although less frequently. As students put it, "We had a theme every time and [we] wanted [them] to learn, to understand what it is to talk about equality, about truth, about friendship".

Q7. Do you think the program benefited you in some way?

When asked whether they thought the program benefited them, most students suggested they think their ability for "enquiry", "critical thinking" and "argumentation" has improved. As one student said: "Now I examine the decision I want to make, the pros, the cons, I think about the consequences, I ask others and listen to them, I participate, I see if it is all right and if it isn't... I retreat!”. The improvement of linguistic and dialogue skills was also perceived as a consequence of the program quite often (Table 8). In students' own words, "I was talking very immaturely before”, "I can discuss better now”. Finally, some students integrated within the program's

\begin{tabular}{cc} 
Table 6. Categories of student’s responses to Q5. \\
\hline Categories of students' responses to Q5 & Frequency (times of appearance) \\
\hline Yes: Interesting topics, deep analysis & 11 \\
Yes: Experience in enquiry \& critical thinking & 7 \\
Yes: Joy & 6 \\
Yes: Exercise in dialogue & 5 \\
Yes: Sense of community & 4 \\
Yes: Help with school courses & 1
\end{tabular}

Table 7. Categories of student's responses to Q6.

\begin{tabular}{cc}
\hline Categories of students' responses to Q6 & Frequency (times of appearance) \\
\hline Dialogue, discussion, tolerance & 11 \\
Enquiry, critical thinking, argument & 6 \\
Clarification of concepts & 3 \\
\hline
\end{tabular}


benefits a better understanding of the concepts discussed: "I learned a lot about friendship, equality, right and wrong", "I understand [those] concepts better".

Q8. Do you feel you act differently in some way during a discussion now (say in school or at home) in which people express different opinions?

Students were asked whether they feel they now act differently in some way during a discussion in which people express different opinions. Most of them (14) said they do. They feel that they are more willing to "enquire" and explore "alternative" views and their grounds without prejudice: they will "try to see all sides" and "think of the consequences", they will "try to find arguments, good arguments", or they won't "rush in to defend whatever [their] best friend is saying or whatever suits [them] as [they] did before" (Table 9). 2 students however, did not reply to this question.

\subsection{Students' Suggestions for Changes}

Students were asked about any changes they would suggest regarding the program in general (Q9) and its duration in particular $(\mathrm{Q} 10)$.

Q9. If we run a similar program next year, what changes would you like to make?

When asked what changes they would like us to make to the program, 7 students replied there was nothing to be changed. The rest of the children however, made several suggestions (Table 10).

More specifically, some students suggested that we should prepare more meetings and more topics ("more dilemmas", "more enigmas" and "more discussions"). It has also been suggested that we would accommodate more children as participants, so that there would be "more points of view of each topic". Students proposed twice that we should "reach some conclusion in the end" and also twice that we should set stricter rules in our debates considering how much time each would speak or how to take turns.

Table 8. Categories of student's responses to Q7.

\begin{tabular}{cc}
\hline Categories of students' responses to Q7 & Frequency (times of appearance) \\
\hline Improved enquiry, critical thinking, argument & 10 \\
Improved dialogue \& linguistic skills & 7 \\
Improved understanding of concepts & 2 \\
\hline
\end{tabular}

Table 9. Categories of student’s responses to Q8.

\begin{tabular}{cc|}
\hline Categories of students' responses to Q8 & Frequency (times of appearance) \\
\hline Enquiry: alternatives/arguments & 14 \\
No response/I don't know & 2 \\
\hline
\end{tabular}

\section{Table 10. Categories of student's responses to Q9.}

\begin{tabular}{cc}
\hline Categories of students' responses to Q9 & Frequency (times of appearance) \\
\hline No change & 7 \\
More topics & 4 \\
More children \& points of view & 4 \\
Reach a conclusion & 2 \\
Stricter dialogue rules & 2 \\
Real life simulations of thought experiments & 2 \\
No science fiction thought experiments & 1 \\
Outdoors sessions & 1 \\
Integration in school hours/curriculum & 1 \\
\hline
\end{tabular}


Twice they suggested we have "simulations" of the thought experiments so that students would really experience what would be like if they found themselves in the situation under investigation. Both of those who suggested "real life simulations" had in mind the trolley problem; they suggested we made some trial with a bicycle so that they could see what they would really do in a similar situation: "I could sit right here with some of the others, and one could come towards us with the bike, and another should decide if they should push us or throw down the biker or what".

Moreover, it was suggested that science fiction thought experiments should be excluded from any future program. As one student said, he "would like the robot to go away”. We should note that during the final group discussion more children said they preferred everyday-life stories as triggers rather than science fiction stories with robots. It seems that some children found science fiction thought experiments disturbing; nevertheless, we feel they were actually drown by them: there were vivid discussions about what differentiated those stories with real-life circumstances and as a result they remembered them with a bit of anxiety.

Having outdoors sessions was a suggestion as well. One student "would rather we did not do it at school next year". She felt it would be best to do it someplace else to "go outside, away from the school-culture". On the contrary, another student said she would prefer the sessions to take place during school-week and be more attached to the actual school-program: "to be a school-course; just like the other things we do at school".

Q10. Are you happy with the number of meetings? Would you rather there were more or less meetings?

When asked whether they were happy with the number of meetings, most of the students said "it was fine" (Table 11). Nevertheless, 5 students said they wanted more meetings so that they "could discuss more on each topic" or that they "could discuss more topics". And finally, just one student did not reply.

\section{Discussion}

Our main question was to see how children experienced their participation in the program we outlined earlier in this paper; whether they liked the program but also what they felt its purpose and its benefits were, and what they would like us to change next time.

Our findings suggest that the students enjoyed the program. On top of that, they think we aimed at improving their thinking and argumentative skills, their linguistic and dialogical skills, while also helping them create a community. Finally, they also feel they were benefited in the ways mentioned above. Thus, they feel their critical thinking skills and their dialogical skills were sharpened; they feel they enquire, talk and argue better; they also feel they were part of a community of enquiry; they feel they became more tolerant to different opinions and more open-minded. Students have thus grasped most of the typical goals of P4C programs; and they claim they achieved them.

It should be clear however, that this is not our claim. We do not suggest we actually achieved these goals. We cannot say if they truly changed or improved their thinking, dialogical, linguistic or argumentative skills; we cannot say whether their attitudes towards different opinions altered in any way; and, even if there was a change in their attitudes, we have no way of knowing how long this change has lasted or will last. All such things are difficult to measure; and in any case, it is doubtful that ones' overall thinking habits may change after just a few sessions.

Yet, we do claim that what students said in their interviews matters. For one thing, they truly enjoyed the program. Most of their responses suggest so. And it is not just their explicit statements; our overall experience suggests that we all enjoyed those 8 meetings. Besides, all participants (us included) travelled several kilometers to school every Sunday morning, just for the sessions. None of us had any other gain or reward whatsoever (e.g. funding, bonus, etc.). In fact, students liked it so much that hardly ever did anyone miss a session. Of course, some also got a bit bored sometimes “depending on the [their] mood”, and many claim they felt a feeling of

Table 11. Categories of student's responses to Q10.
\begin{tabular}{cc}
\hline Categories of students' responses to Q10 & Frequency (times of appearance) \\
\hline I'm OK with the number of meetings & 5 \\
I'd like more meetings & 1 \\
No answer & 1 \\
\hline
\end{tabular}


“discomfort”. Nevertheless, they kept coming. And we should note that even when they talk about "discomfort", they seem to have appreciated the feeling as something disturbing and unusual, yet welcomed and useful.

Moreover, most of the participants were not "good students": their marks were low; some even had trouble being promoted in the next grade. This positive attitude toward the program might be because they felt nice to have fun at school for a change. Even more importantly perhaps, they felt proud, accountable and free; might be a sense of accomplishment, a sense that somebody asks what you think of this important topic and have a group of people discussing what you said.

Secondly, it was surprising that children grasped P4C's typical goals, even though we never mentioned them explicitly. Through a series of discussions about different topics, they did see P4C's objective to both "challenge the mind and cultivate the heart". And they came to appreciate these goals, asking for more such programs, both in and outside the school curriculum.

In fact, they didn't just grasp P4C's pedagogical objectives to foster specific skills; some also came to appreciate philosophy's own value as well. Many mention how they enjoyed deep thinking, clarifying concepts, exploring different viewpoints, giving arguments and counter-arguments. They participated in some of the methods of philosophy and they felt it help them reach a better understanding of the topics we discussed and the related concepts.

Last, but not least, students seem to believe they advanced some of their character traits as well. They imply they have cultivated virtues, such as open-mindedness, intellectual courage, tolerance, and accountability. These virtues are both epistemic and moral (Zagzebski, 1996; Montmarquet, 1987, 1993; Code, 1984, 1987; Kotzee, 2013). And to appreciate them indicates starting to develop them. Children spontaneously came to realize such traits as ideals. And this amounts to promoting them.

During the philosophy sessions, children discussed philosophical questions and they came to appreciate moral ideals just through the discussion; that is without any kind of indoctrination. We didn't ever mention or even imply that tolerance or open-mindedness was among the program's goals; children seem to have picked it up just because they enjoyed being in a tolerant, open-minded environment. Challenging the mind then, seems to lead to the cultivation of heart. And vice versa, the cultivation of heart challenges the mind. Being in a tolerant, open-minded environment also helped students realize that thinking and linguistic skills do matter. In a true democratic trusting community, one can only rely on their own mind and language to articulate and justify their views, as well as persuade the others.

From what they claimed in the interview then, they seem to care about the skills philosophy sessions foster; in fact, part of their motivation to participate in the first place, then stay in the program and even be willing to try it again next year, comes from their belief that it can help them think, argue and discuss better. They seem to value these skills outside philosophy sessions as well. And they feel philosophy can help them advance such skills, so that they can then use them in real life problems. This however, does not imply they see philosophy as a pure means to another end. On the contrary, they seemed to enjoy philosophizing. They liked thinking of alternative viewpoints or examining abstract concepts. In fact, some even enjoy the discomfort philosophy is sometimes associated with.

Very often we heard the participants say that they now think about what they or other people say. They ask for reasons and arguments for their own claims and if they find them poor, they prefer to “.... retreat!" as they say. All such statements show that up to a point they would like to be able to think about their thoughts and reasons; in other words, they value meta-cognitive skills and they wish to develop them.

Also, their interviews show that students enjoyed the try. Even when they felt overwhelmed or tired, none quit the program. On the contrary, they all kept coming to the sessions, discussing more on them with friends and family and reflecting on them when alone. And what's more, they wanted to do it again. Whether their metacognitive skills are fully developed or not, they didn't seem to feel particularly pressured or find the discussions too demanding for them to cope.

Nonetheless, among the findings of this program, we should also appreciate the optimistic bias that seems at play here. Children probably think they benefited much more than they actually did. And the same, more or less, goes for us as well. During those 8 weeks we felt a strong sense of accomplishment, even though there were no solid grounds that children improved their skills or character.

We fully realize that it takes much more than a few philosophy sessions in order to achieve any of these goals the children set for themselves. In fact, we probably need to totally re-design our schools. In the meantime however, such programs could help change some children's perception of education and appreciate the values of 
discussing, thinking, and inquiring both as epistemic and as moral virtues. After all, realizing the importance of such virtues is the starting point for cultivating them.

\section{Acknowledgements}

We would like to thank the students of Lappa High school who participated in the study. Also, we thank our students in the University of Patras, Christina Aggelakopoulou, Christina Gotsi and Marini Geli, who helped us with the interviews' transcriptions. Most of all, we would like to thank the two teachers of Lappa High school's "environmental club" in which we integrated our program, Eleonora Papadopoulou and Evaggelia Chousakou. Without them, the whole project would have been impossible. In fact, we would like to dedicate this paper to the memory of Evaggelia, who left us so early.

\section{References}

Biesta, G. (2011). Philosophy, Exposure, and Children: How to Resist the Instrumentalisation of Philosophy in Education. Journal of Philosophy of Education, 45, 305-319. http://dx.doi.org/10.1111/j.1467-9752.2011.00792.x

Code, L. (1984). Toward a “Responsibilist” Epistemology. Philosophy and Phenomenological Research, 45, 29-50. http://dx.doi.org/10.2307/2107325

Code, L. (1987). Epistemic Responsibility. Hanover: University Press of New England and Brown University Press.

Daniel, M. F., \& Delsol, A. (2005). Learning to Dialogue in Kindergarten: A Case Study. Analytic Teaching, 25, $23-52$.

Daniel, M. F., \& Gagnon, M. (2011). Developmental Process of Dialogical Critical Thinking in Groups of Pupils Aged 4 to 12 Years. Creative Education, 2, 418-428. http://dx.doi.org/10.4236/ce.2011.25061

Daniel, M. F., Pettier, J. C., \& Auriac-Slusarczyk, E. (2011). The Incidence of Philosophy on Discursive and Language Competence in Four-Year-Old Pupils. Creative Education, 2, 296-304. http://dx.doi.org/10.4236/ce.2011.23041

Fisher, R. (2001). Philosophy in Primary Schools: Fostering Thinking Skills and Literacy. Reading, 35, 67-73. http://dx.doi.org/10.1111/1467-9345.00164

Follman, J., Lavely, C., \& Berger, N. (1997). Inventory of Instruments of Critical Thinking. Informal Logic, 18, $261-267$.

Gregory, M. (2011). Philosophy for Children and Its Critics: A Mendham Dialogue. Journal of Philosophy of Education, 45, 199-219. http://dx.doi.org/10.1111/j.1467-9752.2011.00795.x

Gregory, M. R. (2007). A Framework for Facilitating Classroom Dialogue. Teaching Philosophy, 30, 59-84. http://dx.doi.org/10.5840/teachphil200730141

Haynes, J. (2008). Children as Philosophers. London: Routledge.

Haynes, J., \& Murris, K. (2012). Picturebooks, Pedagogy and Philosophy. London: Routledge.

Johnson, R. B., \& Christensen, L. B. (2004). Educational Research: Quantitative, Qualitative, and Mixed Approaches. Boston, MA: Allyn and Bacon. http://dx.doi.org/10.3102/0013189X033007014

Kotzee, B. (Ed.) (2013). Education and the Growth of Knowledge: Perspectives for Social and Virtue Epistemology. London: Willey Blackwell. http://dx.doi.org/10.1002/9781118721254

Kuhn, D., \& Park, S. H. (2005). Epistemological Understanding and the Development of Intellectual Values. International Journal of Educational Research, 43, 111-124. http://dx.doi.org/10.1016/j.ijer.2006.05.003

Lipman, M. (1982). Philosophy for Children. Thinking, 3, 37-47.

Lipman, M. (1988). Philosophy Goes to School. Philadelphia, PA: Temple University Press.

Lipman, M. (1991). Thinking in Education. Cambridge, MA: Cambridge University Press.

Matthews, G. (1980). Philosophy and the Young Child. Cambridge, MA: Harvard University Press.

Montmarquet, J. (1993). Epistemic Virtue and Doxastic Responsibility. Lanham, MD: Rowman \& Littlefield.

Montmarquet, J. (1987). Epistemic Virtue. Mind, 96, 482-497. http://dx.doi.org/10.1093/mind/XCVI.384.482

Murris, K. (2000). Can Children Do Philosophy? Journal of Philosophy of Education, 34, 261-279. http://dx.doi.org/10.1111/1467-9752.00172

Reznitskaya, A. (2012). Dialogic Teaching: Rethinking Language Use during Literature Discussions. The Reading Teacher, 65, 446-456. http://dx.doi.org/10.1002/TRTR.01066

Reznitskaya, A., Glina, M., Carolan, B., Michaud, O., Rogers, J., \& Sequeira, L. (2012). Examining Transfer Effects from Dialogic Discussions to New Tasks and Contexts. Contemporary Educational Psychology, 37, 288-306.

http://dx.doi.org/10.1016/j.cedpsych.2012.02.003 
Reznitskaya, A., Kuo, L., Clark, A., Miller, B., Jadallah, M., \& Anderson, R. C. (2009). Collaborative Reasoning: A Dialogic Approach to Group Discussions. Cambridge Journal of Education, 3, 29-48. http://dx.doi.org/10.1080/03057640802701952

Reznitskaya, A., Anderson, R. C., Dong, T., Li, Y., Kim, I. H., \& Kim, S. Y. (2008). Learning to Think Well: Application of Argument Schema Theory. In C. C. Block, \& S. Parris (Eds.), Comprehension Instruction: Research-Based Best Practices (pp. 196-213). New York: Guilford Press.

Riley, S. (2013). Building a High School Philosophy Program. Teaching Philosophy, 36, 239-252. http://dx.doi.org/10.5840/teachphil201336332

Splitter, L. J., \& Sharp, A. M. (1995). Teaching for Better Thinking: The Classroom Community of Enquiry. Melbourne: Acer.

Stokes, P. (2012). Philosophy Has Consequences! Developing Metacognition and Active Learning in the Ethics Classroom. Teaching Philosophy, 35, 143-169. http://dx.doi.org/10.5840/teachphil201235216

Topping, K. J., \& Trickey, S. (2007). Impact of Philosophical Enquiry on School Student's Interactive Behavior. Thinking Skills and Creativity, 2, 73-84. http://dx.doi.org/10.1016/j.tsc.2007.03.001

Trickey, S., \& Topping, K. J. (2004). Philosophy for Children: A Systematic Review. Research Papers in Education, 19, 365-380. http://dx.doi.org/10.1080/0267152042000248016

White, J. (2012). Philosophy in Primary Schools? Journal of Philosophy of Education, 46, 449-460. http://dx.doi.org/10.1111/j.1467-9752.2012.00860.x

Worley, P. (2011). The If Machine. London: Continuum.

Youssef, C. (2014). A Multilevel Investigation into the Effects of the Philosophical Community of Inquiry on 6th Grade Students' Reading Comprehension, Interest in Maths, Self-Esteem, Pro-Social Behaviors and Emotional Well-Being. Ph.D. Thesis, School of Cultural and Professional Learning, Queensland University of Technology, Faculty of Education, Brisbane: Queensland.

Zagzebski, L. T. (1996). Virtues of the Mind. Cambridge: Cambridge University Press. http://dx.doi.org/10.1017/CBO9781139174763

\section{Appendix}

\section{The Interview Protocol}

1) Why did you choose to participate in this program in the first place?

2) Did you enjoy the P4C sessions?

3) How did you feel during the discussions?

4) How did you feel after the discussions? Did you think about what you discussed?

5) If we run a similar program next year, would you like to take part in it?

6) What do you think was the purpose of this program? Is there something you believe we wanted you to learn or understand?

7) Do you think the program benefited you in some way?

8) Do you feel you act differently in some way during a discussion now (say in school or at home) in which people express different opinions?

9) If we run a similar program next year, what changes would you like to make?

10) Are you happy with the number of meetings? Would you rather there were more or less meetings? 